\title{
Incorporating Disease-Oriented Smoking Cessation Education into the Care of Smokers with Peripheral Arterial Disease
}

Donte J Newsom

Follow this and additional works at: https://researchrepository.wvu.edu/etd

\section{Recommended Citation}

Newsom, Donte J, "Incorporating Disease-Oriented Smoking Cessation Education into the Care of Smokers with Peripheral Arterial Disease" (2018). Graduate Theses, Dissertations, and Problem Reports. 7220.

https://researchrepository.wvu.edu/etd/7220

This Dissertation is protected by copyright and/or related rights. It has been brought to you by the The Research Repository @ WVU with permission from the rights-holder(s). You are free to use this Dissertation in any way that is permitted by the copyright and related rights legislation that applies to your use. For other uses you must obtain permission from the rights-holder(s) directly, unless additional rights are indicated by a Creative Commons license in the record and/ or on the work itself. This Dissertation has been accepted for inclusion in WVU Graduate Theses, Dissertations, and Problem Reports collection by an authorized administrator of The Research Repository @ WVU.

For more information, please contact researchrepository@mail.wvu.edu. 
Incorporating Disease-Oriented Smoking Cessation Education into the Care of Smokers with Peripheral Arterial Disease

Donte J. Newsom, DNP, APRN

Final Project submitted to the School of Nursing at West Virginia University

in partial fulfillment of the requirements for the degree of Doctor of Nursing Practice

Joy Buck, Ph.D., APRN, Committee Chair Martha Summers, DNP, APRN, FNP-BC, Committee Member Issaiah Wallace, BSN, RN, TTS, Committee Member

\title{
Department of Nursing
}

\author{
Morgantown, West Virginia
}

2018

Keywords: peripheral arterial disease, smoking cessation, brief interventions Copyright 2018 Donte J. Newsom, DNP, APRN 


\section{ABSTRACT \\ Incorporating Disease-Oriented Smoking Cessation Education into the Care of Smokers with Peripheral Arterial Disease}

\section{Donte Newsom}

\section{Background and Significance}

Smoking is a major health issue in the United States, with nearly $18 \%$ of the population being reported as active smokers. Smoking is a contributing factor to many chronic diseases, such as peripheral arterial disease, and is a public health concern significant to nursing practice.

\section{Problem Statement}

Despite evidence of the detriments of smoking, many patients with peripheral arterial disease receive minimal smoking cessation education, and cessation aides are rarely utilized.

\section{Project Design}

A disease-oriented smoking cessation education intervention was developed modeling the 5 A's of smoking cessation and utilized for active smokers with peripheral arterial disease. This pilot study evaluated the feasibility of implementing the practice change in a specialty practice.

\section{Evaluation Plan}

Patients' number of cigarettes smoked daily, readiness to change, and attitudes towards the intervention were evaluated. Percent of eligible people who obtained the intervention were tracked to evaluate process. The cost-effectiveness of the intervention was a major consideration.

\section{Results}

The intervention reached $69 \%$ of those who met inclusion criteria. Most participants found the intervention helpful. Participants reduced smoking by $60.8 \%$ and moved forward toward smoking cessation by 1.0 stage of change. A cost/benefit analysis revealed the intervention was cost-effective.

\section{Recommendations}

This cost-effective practice change should be implemented across a variety of practice settings as part of comprehensive healthcare approach to smoking cessation. 


\section{Acknowledgements}

I offer my deepest appreciation and sincere thanks to Dr. Joy Buck as the chairperson of my committee for the time, support, wisdom, and encouragement throughout the course of this project. To Dr. Summers as the director of the program and committee member who offered advice, time, and understanding. To Issaiah Wallace, committee member, for his selflessness, time, and content knowledge he provided while completing a challenging program concurrently. And to Dr. Sam Cotton, faculty, who provided the encouragement and vision to move forward in the program.

To my loved ones, I could never offer enough thanks for the blessing of the gift of life and the feeling of eternal love from my mother Linda, whose tireless will, uncommon kindness, and educational spirit allowed me to become everything I aspired to be. To my father Roger who has always believed in me, showed true pride, and helped me appreciate the struggles in life. To my older siblings Brandon and Chanelle for providing encouragement and footsteps to follow. For Aiden, my younger brother, who makes me laugh and strive to be someone to look up to. Lastly, thank you to my partner Brad, who endured, sacrificed, encouraged, loved, and provided needed comfort throughout my endeavor. And to the rest of my family, friends, and coworkers who may not be named but would never go unrecognized in my mind or heart. I am grateful for my many blessings. 


\section{Table of Contents}

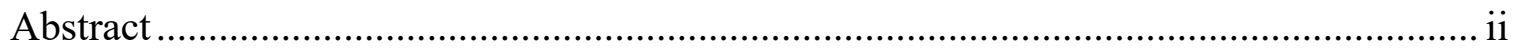

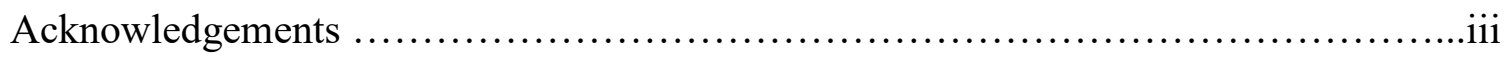

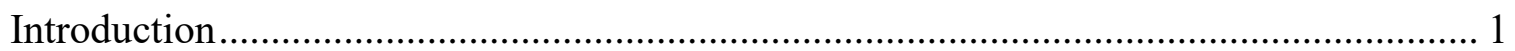

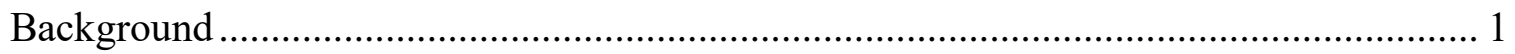

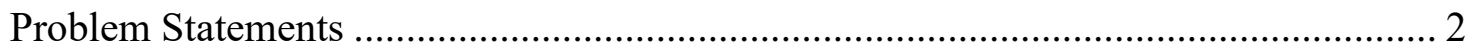

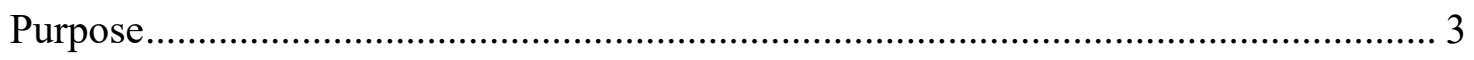

Significance of the Project ................................................................................... 4

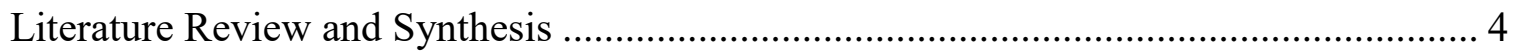

Peripheral Arterial Disease, Smoking, and Smoking Cessation ................................ 5

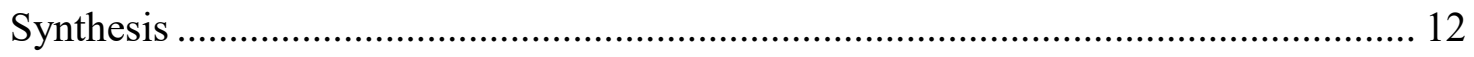

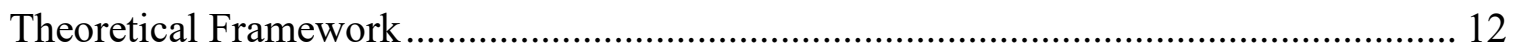

Figure 1. Transtheoretical Model of Health Behavior Change ...................................... 14

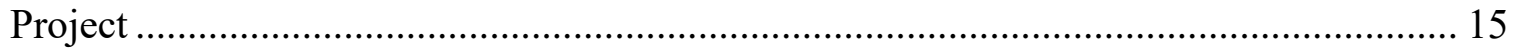

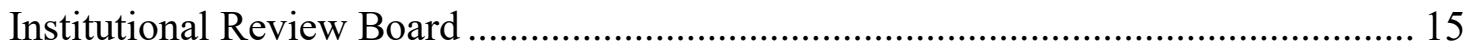

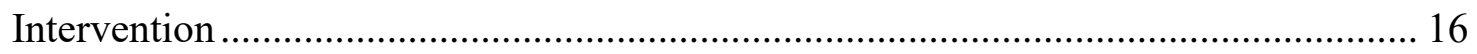

The Transtheoretical Model and Smoking Cessation ............................................ 21

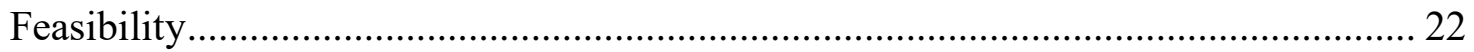

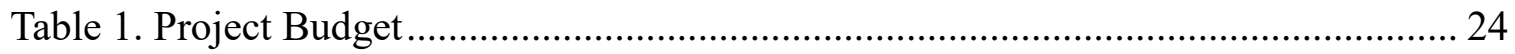

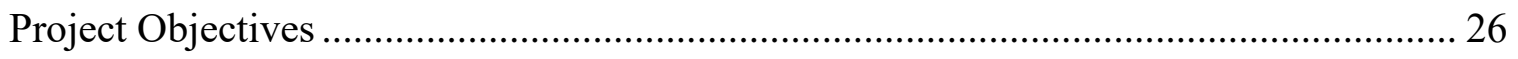




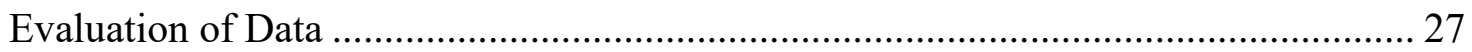

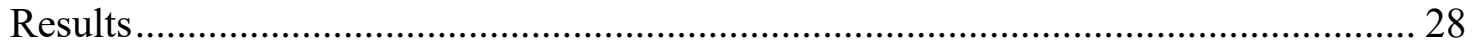

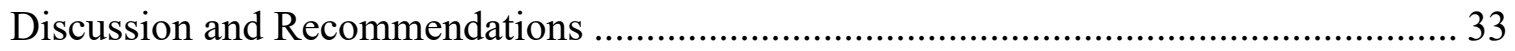

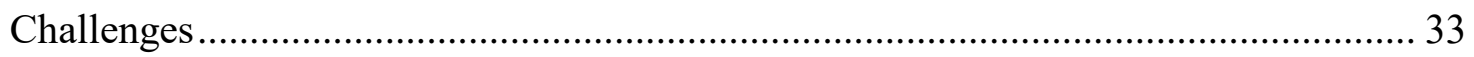

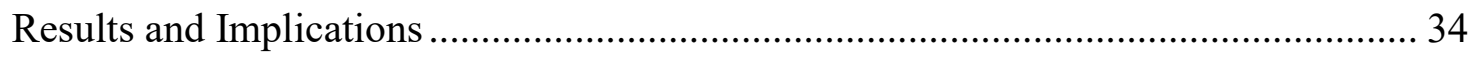

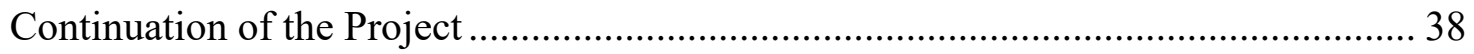

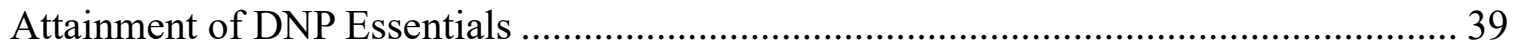

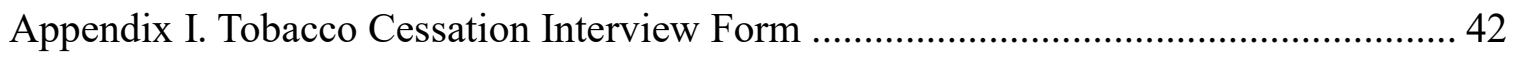

Appendix II. Descriptive Questions.............................................................. 44

Appendix III. Qualitative Interview Questions..................................................... 45

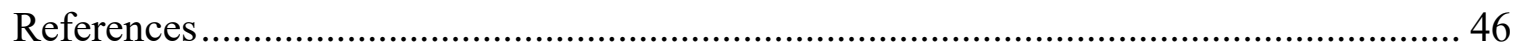


Incorporating Disease-Oriented Smoking Cessation Education into the Care of Smokers with

\section{Peripheral Arterial Disease}

Smoking is a major public health hazard that is of concern to all levels of nursing practice. Prevention is a key role of the advanced practice nurse, and smoking is a preventable risk factor for many diseases. One of the many diseases that is attributable to smoking is peripheral arterial disease (Hennrikus et al., 2010). Despite evidence of the detriments of smoking, many patients receive minimal education related to smoking cessation, and cessation aides are rarely utilized (Aiman et al., 2014; Mannava \& Money, 2007; Verma et al., 2011). This project evaluated the feasibility of implementing an intervention that identified current smokers with peripheral arterial disease in a small specialty practice and provided them with diseaseoriented smoking cessation education to help prevent disease recurrence or worsening.

\section{Background}

Working as a nurse practitioner at a small vascular surgery practice in North Central West Virginia offers many challenges, but also many opportunities. The patient population is rural, $97 \%$ white, and the majority are from a lower socioeconomic background. Almost $24 \%$ of patients are current smokers, with an additional $38 \%$ being former smokers. Only $37 \%$ of patients have never smoked. Despite its challenges, being able to work and help patients from one's own community is often rewarding. The providers and staff are committed to providing excellent patient care to patients diagnosed with a variety of vascular diseases, such as abdominal aortic aneurysms, carotid artery disease, peripheral arterial disease, venous insufficiency, and wounds. Among these, peripheral arterial disease is the most prevalent and lifestyle impacting disease and was the focus for the purposes of this project. 


\section{Problem Statements}

Smoking is a major health issue in the United States, with nearly $18 \%$ of the United States population being reported as active smokers (CDC, 2015). Smoking is a leading contributor to death and disease. More than 16 million people in the U.S. have diseases caused by smoking, and one in five deaths in the U.S. are caused by smoking, totaling nearly 480,000 each year. Subsequently, smoking is a major economic burden, costing the medical system $\$ 193$ billion a year (HealthyPeople.gov).

Peripheral arterial disease (PAD) is a vascular disorder involving the narrowing of the arterial blood vessels distal to the aortic arch (Sontheimer, 2006). The reported prevalence of PAD varies widely between studies and is affected by age and other risk factors; it affects 3-10\% of the general population, and $15-20 \%$ of adults over 70 years of age (Hennion \& Siano, 2013). In one study, when evaluating smoking in the sub-population of people with peripheral arterial disease, it was found that approximately $26 \%$ smoke, and as many as $79 \%$ have a smoking history, either current or former (Dunkley, et al., 2007). Smoking is a top modifiable risk factor contributing to PAD, second only to diabetes (Alexopoulos, Vlachopoulos, \& Stefanadis, 2010; Conen et al., 2011; Hennrikus et al., 2010; Federman and Kravetz, 2007; Katsiki, Papadopoulou, Fachantidou, \& Mikhailidis, 2013; Lu, Mackay, \& Pell, 2014; Moyer, 2013; Muir, 2009; Paraskevas, Papas, Pavlidis, Bessias, \& Andrikopoulos, 2008; Simmons, Steffen, \& Sanders, 2012; Sontheimer, 2006; Steffen, Duprez, Boucher, Ershow, \& Hirch, 2008; Verma, Prasad, Elkadi, \& Chi, 2011;Watson, Watson, \& Pater, 2006; Wiley, Kumar, \& Vacek, 2012). Increased pack years of smoking increases the risks of developing PAD, and increases the morbidity and mortality of the diagnosis, demonstrating a dose-dependent relationship between the two (Au, Golledge, Walker, Haigh, \& Nelson, 2013; Hankey, Norman, \& Eikelboom, 2006; Katsiki et al., 
2013; Lee et al., 2011; Paraskevas et al., 2008; Watson, Watson, \& Pater, 2006). Additionally, former smokers, or individuals who quit smoking more than 10 years ago, may still have increased risk of developing PAD and suffering increased morbidity and mortality (Aboyans et al., 2011; Conen et al., 2011; Lu, Mackay, \& Pell, 2014; Verma et al., 2011). Finally, smoking increases the inherent risks of PAD, including leg amputation, coronary artery disease, stroke, and mortality (Madia, 2012; Steffen et al., 2008; Verma et al., 2011).

There have been few randomized controlled trials (RCTs) of methods of smoking cessation specifically for patients with peripheral arterial disease (Hankey et al., 2006; Hennion \& Siano, 2013; Hennrikus et al., 2010). However, smoking cessation improves the morbidity and slows disease progression by increasing walking distance, doubling five-year survival rates, and reducing the incidence of post-operative complications (Au et al., 2013; Hennrikus et al., 2010; Katsiki et al., 2013). Clinical practice guidelines offer strong evidence-based recommendations supporting smoking cessation interventions for patients with PAD. There is also consensus evidence in favor of screening patients 50 years and older who have a history of smoking for PAD (Hennion \& Siano, 2013; Layden, et al, 2012; Moyer, 2013). Unfortunately, there is still a large percentage of patients with PAD that are not treated adequately with riskfactor reduction such as smoking cessation (Aiman et al., 2014; Federman and Kravetz, 2007; Lumsden and Rice, 2006).

\section{Purpose}

The purpose of this project was to evaluate the feasibility of implementing an intervention that identifies current smokers with peripheral arterial disease (PAD) in a small specialty practice and providing them with disease-oriented smoking cessation education to help prevent disease recurrence or worsening. 


\section{Significance of the Project}

Smoking is a key modifiable risk factor linked to the development of peripheral arterial disease, yet a large percentage of patients who are identified as current smokers do not receive smoking cessation education and are under diagnosed and undertreated (Mannava \& Money, 2007; Aiman, et al., 2014). The goal of this project was to identify current smokers with peripheral arterial disease and provide them with disease-oriented smoking cessation education to help prevent disease recurrence or worsening. Providing disease-oriented smoking cessation education meant that patients received smoking cessation education that focused on how smoking impacts their disease process, and how quitting could improve their symptoms and health outcomes. It was proposed that creating an informational link through disease-oriented smoking cessation education may help patients reduce or eliminate their smoking. For example, it is known that smoking cessation improves symptoms of PAD such as walking distance and claudication and reduces disease recurrence and overall disease morbidity and mortality (Au et al., 2013; Katsiki et al., 2013). Educating patients on the benefits of smoking cessation to improve their current symptoms and health likely increased their likelihood of quitting.

\section{Literature Review and Synthesis}

A systematic review of the literature of the relationship between smoking cessation interventions and peripheral artery diseases was conducted in July of 2016 utilizing EBSCOHost with CINHAL, HealthSource: Nursing/Academic Edition, Academic Search Complete, MEDLINE, PsychINFO and PsychArticles as the selected databases. "Smoking cessation" and "vascular surgery", "smoking cessation" and "interventions", "smoking cessation interventions" and "peripheral arterial disease", and "smoking cessation" and "peripheral arterial disease" were the mesh terms used for the search. Peer reviewed, English language articles about smoking and 
smoking cessation as it related to peripheral arterial disease compromised the inclusion criteria. Exclusion criteria included studies that did not relate to smoking or smoking cessation and PAD, non-English articles, and non-peer-reviewed articles. A total of 34 articles were included in this brief review of the literature.

\section{Peripheral Arterial Disease, Smoking, and Smoking Cessation}

Numerous articles related to smoking and peripheral arterial disease were reviewed to gain a broad understanding of the literature related to smoking and smoking cessation's impact on peripheral arterial disease. Peripheral arterial disease is the presence of systemic atherosclerosis in arteries distal to the aortic arch (Sontheimer, 2006). It most often affects the arteries that supply the legs, but also can occur in the arms, brain, stomach, kidney, or other vital organs (Steffen et al., 2008). Peripheral arterial disease of the extremities is diagnosed clinically by the ankle brachial index (ABI), a diagnostic tool which is assessed with standard protocols and calculates the index using a ratio of the highest systolic blood pressure in the arm compared with the highest systolic pressure in the legs. Peripheral arterial disease is defined by an ABI of 0.90 or less, and the ABI is associated with high sensitivity and specificity (Aboyans et al., 2011; Aiman et al., 2014; Aronow, 2007a; Aronow, 2007b; Aronow, 2010; Federman and Kravetz, 2007; Hankey et al., 2006; Hennion \& Siano, 2013; Hennrikus et al., 2010; Hiatt \& Krantz, 2006; Kroger et al., 2009; Lee et al., 2011; Madia, 2012; Moyer, 2013; Simmons, Steffen, \& Sanders, 2012; Sontheimer, 2006; Steffen et al., 2008; Verma et al., 2011; Watson, Watson, \& Pater, 2006; Wiley, Kumar, \& Vacek, 2012). Low ABIs have been proven to be an independent risk factor of cardiovascular risk and as a predictor for future cardiac events such as coronary artery disease, stroke, and death (Aronow, 2007; Hankey et al., 2006; Steffen et al., 2008). 
Pathophysiology. Major pathophysiological factors involved in the peripheral arterial disease (PAD) include platelet activation and thrombosis, along with arterial stiffness. As lesions develop and increase in complexity, additional factors such as ulceration, rupture, or erosion also occur (Alexopoulos, Vlachopoulos, \& Stefanadis, 2010; Watson, Watson, \& Pater, 2006). Risk factors such as cigarette smoking contribute further to the process due to constriction and damage of arteries which potentiates endothelial dysfunction and alters lipoprotein metabolism, coagulation, and platelet function (Lee et al., 2011). Other studies discuss the response to injury model of atherosclerosis, which links smoking to endothelial dysfunction, leading to an inflammatory host response that leads to vascular remodeling, followed by plaque formation, and eventually a complicated atherosclerotic lesion (Haugen, Casserly, Regensteiner, \& Hiatt, 2007). Passive smoking has also been associated with increased arterial stiffness (Katsiki et al., 2013). Current smoking, diabetes, BMI, blood pressure, and cholesterol are the most relevant mediators of PAD (Aboyans et al., 2011; Aronow, 2007a; Aronow, 2007b; Aronow, 2010; Federman and Kravetz, 2007; Hankey et al., 2006; Hennion \& Siano, 2013; Hiatt \& Krantz, 2006; Kroger et al., 2009; Lovell, Myers, Forbes, Dresser, \& Weiss, 2011; Lumsden and Rice, 2006; Madia, 2012; Mannava \& Money, 2007; Moyer, 2013; Muir, 2009; Simmons, Steffen, \& Sanders, 2012; Steffen et al., 2008; Verma et al., 2011; Watson, Watson, \& Pater, 2006; Wiley, Kumar, \& Vacek, 2012).

Significance. Peripheral arterial disease (PAD) is associated with a number of detrimental health effects such as amputation, heart attack, stroke, and death (Aiman et al., 2014; Alexopoulos, Vlachopoulos, \& Stefanadis, 2010; Aronow, 2007a; Aronow, 2007b; Aronow, 2010; Haugen et al., 2007; Hennion \& Siano, 2013; Hiatt \& Krantz, 2006; Lee et al., 2011; Lovell et al., 2011; Moyer, 2013; Muir, 2009; Simmons, Steffen, \& Sanders, 2012; Steffen et al., 
2008; Verma et al., 2011; Watson, Watson, \& Pater, 2006; Wiley, Kumar, \& Vacek, 2012).

Notably, people with PAD had a 30\% increase in risk of death within five years, and 50\% within ten years, mostly secondary to myocardial infarction (Dunkley, Stone, Sayers, Farooqi, \& Khunti, 2007; Hankey et al., 2006). Additionally, peripheral arterial disease is associated with a decreased quality of life (Watson, Watson, \& Pater, 2006; Wiggers et al., 2006). Factors such a low socioeconomic status have been associated with higher cardiovascular morbidity and mortality when compared to the population and several articles recommend prevention programs that specifically target individuals of lower income and education (Aiman et al., 2014; Kroger et al., 2009).

Despite the evidence, many patients with PAD remain untreated (Aiman et al., 2014; Mannava \& Money, 2007; Verma et al., 2011). Furthermore, less than one in four Americans under 50 were aware of the existence of PAD, and 50\% of people did not know that risk factors such as diabetes and smoking increased the risks (Steffen et al., 2008).

Smoking and peripheral arterial disease. Peripheral arterial disease (PAD) has many risk factors that contribute to the development and progression of the disease. Among them, smoking has been identified as the single most important modifiable risk factor, known to accelerate the development and progression of the disease and symptoms of the disease such as claudication, which is pain associated with walking that relieves with rest (Hennrikus et al., 2010). As many as $90 \%$ of people with PAD have at least one of the risk factors, either smoking or diabetes (Federman and Kravetz, 2007). Diagnosis of PAD in patients who smoke is made up to a decade sooner than non-smokers and is associated with earlier onset of symptoms (Muir, 2009; Verma et al., 2011). Smoking increased the risk of negative surgical intervention outcomes such as graft failure and restenosis by more than double (Aronow, 2007; Federman and Kravetz, 
2007; Verma et al., 2011; Watson, Watson, \& Pater, 2006). There is a definitive dose-dependent relationship with smoking, meaning that patients with greater pack-years of smoking tend to have increased morbidity and mortality (Au et al., 2013; Hankey et al., 2006; Katsiki et al., 2013; Lee et al., 2011; Paraskevas et al., 2008; Watson, Watson, \& Pater, 2006). Smokers are two to four times more likely to develop PAD and more frequently develop advanced disease complications such as critical limb ischemia and amputation. Past smoking, too, had borderline association with low ABIs (Aboyans et al., 2011; Conen et al., 2011; Lu, Mackay, \& Pell, 2014; Verma et al., 2011). There is evidence that there may be a greater association of smoking to PAD than that of coronary artery disease (Katsiki et al., 2013; Lu, Mackay, \& Pell, 2014; Madia, 2012; Muir, 2009; Steffen et al., 2008; Verma et al., 2011; Watson, Watson, \& Pater, 2006). Additionally, patients with PAD are less likely to receive appropriate treatment of risk factors than those being treated for coronary artery disease (Lumsden and Rice, 2006).

Smoking cessation. Smoking cessation is the most cost-effective treatment available for the treatment of PAD and is widely accepted as one of the main treatment goals for people with PAD who smoke (Katsiki et al., 2013; Wiley, Kumar, \& Vacek, 2012). Smoking cessation improves walking distance, doubles five-year survival rates, and reduces the incidence of postoperative complications (Au et al., 2013; Hennrikus et al., 2010; Katsiki et al., 2013). Continued smoking was found to increase the risk of amputation in patients with PAD, specifically those with intermittent claudication (Aronow, 2007). Poor utilization of smoking cessation interventions by the medical community has been identified in the literature, with recommendations to initiate education on the importance of smoking cessation education earlier, such as in undergraduate programs, and integrate it into the curriculum of medical schools (Aiman et al., 2014). Importantly, while the target is to quit smoking, it has been found that 
cutting down smoking may have beneficial effects (Alexopoulos, Vlachopoulos, \& Stefanadis, 2010). Also, patients who attempt smoking cessation by switching to chewing tobacco were found to have higher rates of mortality than those who chose abstinence (Katsiki et al., 2013).

Smoking cessation interventions. Smoking cessation is an effective but underutilized treatment for peripheral arterial disease. Though there have been few randomized controlled trials (RCTs) of methods of smoking cessation specifically for patients with peripheral arterial disease (Hankey et al., 2006; Hennion \& Siano, 2013; Hennrikus et al., 2010); there are observational data from studies that indicate that smoking cessation is associated with decreased morbidity and reduced disease progression (Hennion \& Siano, 2013). Additionally, clinical practice guidelines offer strong recommendations and have strong evidence in favor of smoking cessation for patients with PAD (Layden, Michaels, Bermingham, Higgins, \& Guideline Development Group, 2012; Simmons, Steffen, \& Sanders, 2012). In their study of patients with PAD, Hennrikus, et al. found that many people who are current smokers are interested in and receptive to formal smoking cessation education programs, and many can successfully quit when provided with the appropriate resources (2010). Their intensive intervention helped $21 \%$ of study participants randomized to the intensive group to quit by utilizing physician advice to quit, counseling related to smoking and the link to PAD, motivational interviewing to increase motivation to quit, cognitive behavioral therapy counseling to develop a quit plan, and information about pharmacological aides for smoking cessation (Hennrikus et al., 2010). In their study of the application of the Chronic Care Model on PAD, a nurse-led team of researchers concluded that nursing involvement in empowering people to make life-changing differences decreased vascular risk factors and improved outcomes for high-risk population as evidenced by significant decreases in the sample's blood pressure and cholesterol, and $16 \%$ of people who 
smoked at baseline successfully quit with the utilization of smoking cessation counseling at every visit and telephone follow-up (Lovell et al., 2011).

Additional literature on brief interventions. Brief interventions refer to practices which identify and address potential problems during short interactions and motivate individuals to change (MDQuit, 2012a). The National Institute for Health and Care Excellence (NICE) guidance offers recommendations related to smoking and brief interventions. The guidance is for practitioners to ask people who smoke how interested they are in quitting, referring those who want to quit to support services, offer smoking cessation aides to those unwilling or unable to accept a referral, be aware of agencies that offer advice and support on how to stop smoking, and have a system in place to know whether patients smoke (NICE, 2006). For smoking cessation, the goal of a brief intervention is to enhance tobacco users' motivation to change and then connect them with evidence-based resources to make their change attempt successful (MDQuit, 2012a). Brief interventions are one step of the well-known public health approach SBIRT, which stands for screening, brief intervention, and referral to treatment (MDQuit, 2012b).

A widely known brief intervention is the "5 A's" approach to smoking cessation. The "5 A's" is a brief, goal-directed method to address tobacco use with patients with the goal of meeting the user's needs in terms of readiness to quit (MDQuit, 2012a). The 5 A's include Ask, Advise, Assess, Assist, and Arrange. The 5 A's can be tailored to the setting and can involve an entire clinic's staff to accomplish the goal of supporting tobacco users. When applying the 5 A's, clinicians (1) ask about tobacco use at each encounter to identify the patient's current use and past smoking patterns; (2) advise patients who are active tobacco users to quit in a clear, strong, personalized manner; (3) assess a patient's willingness to quit using a standardized scale, 
or utilize the stages of change from the Transtheoretical Model of Behavior Change to determine the patient's readiness to change; (4) assist the patient in moving toward a successful quit attempt through a chosen intervention; and (5) arrange follow up contact with the patient, either in person or via telephone to continue support in the quit attempt (MDQuit, 2012a).

Evidence-based practice. Guidelines are collections of evidenced-based recommendations related to specific topics that are published periodically to help guide management of different diseases in the population. Several guidelines are available to help guide the management of peripheral arterial disease (PAD). The National Institute for Health and Care Excellence (NICE), a United Kingdom based organization recommends that all people with peripheral arterial disease receive information, advice, support, and treatment for smoking cessation. For screening, they recommend a thorough vascular history and physical and an Ankle-Brachial Index (ABI) study to assess people who display potential symptoms related to PAD, with no mention of age or risk factors (Layden et al., 2012). The American College of Cardiology and American Heart Association recommend risk factor modification, including smoking cessation, as a major treatment focus. For screening, they recommend the anklebrachial index study for patients with symptoms related to PAD or age 65 and older to be screened, along with people 50 years and older who have a history of smoking or diabetes (Simmons, Steffen, \& Sanders, 2012). Alternatively, the U.S. Preventative Services Task Force does not offer recommendation for screening of asymptomatic adults without a known history of peripheral arterial disease, coronary artery disease, chronic kidney disease, or diabetes. They do, however, note that important risk factors to consider include age, diabetes, smoking, hypertension, high cholesterol, obesity, and physical inactivity (Moyer, 2013). 


\section{Synthesis}

Peripheral arterial disease (PAD), an atherosclerotic disease which affects arterial vessels distal to the aortic arch impacted by atherosclerotic processes which promote platelet activation and thrombosis along with arterial stiffness is defined by an ankle brachial index test less than 0.90. Peripheral arterial disease is present in $3-10 \%$ of the population and is largely impacted by both non-modifiable risk factors such as age and family history, and by modifiable risk factors such as smoking. It is associated with a variety of health problems such as amputations, heart attacks, strokes, death, and a decreased quality of life. Despite its prevalence and ill effects, it is widely under diagnosed and undertreated. Smoking is the top modifiable risk factor for PAD and its presence is shown to make a person two to four times more likely to develop the disease. In addition to increasing prevalence, smoking is known to increase the morbidity and mortality associated with smoking. Alternatively, smoking cessation is the most cost-effective treatment available for the treatment of PAD and is the main treatment goal for patients with PAD who smoke. Smoking cessation interventions should be a standard of care for healthcare organizations which treat patients with PAD.

\section{Theoretical Framework}

The Transtheoretical Model of Health Behavior Change supported the implementation of this system change. The model theorizes that health behavior change involves navigation through six stages of change to integrate processes and principles of change from different theories of intervention. The model's foundations are in multiple leading theories of psychotherapy and behavior change.

There are seven assumptions that lay the foundation for the theory (Prochaska \& Velicer, 1997). The assumptions are as follows: 1) Behavior change is complex and cannot be explained 
fully by any single theory; 2) behavior change develops over time via a sequence of stages; 3 ) stages of change are stable, yet pliable and open to change; 4) populations cannot move from the early stages of change without planned interventions; 5) traditional action-oriented prevention programs are best suited for population who are prepared for action and therefore do not meet the needs of most at-risk populations; 6) to achieve progress through the stages of change, specific processes and principles of change need to be applied at specific stages; 7) biological, social, and self-control are all elements which affect chronic behavior patterns (Prochaska \& Velicer, 1997, p. 41).

The model is defined by several core constructs, including the stages of change, the processes of change, and the concepts of decisional balance, self-efficacy, and temptations (Prochaska \& Velicer, 1997, 39-40). The six stages of change in the model are precontemplation, contemplation, preparation, action, maintenance, and termination. In the precontemplation stage, a person does not intend to make a change in the foreseeable future, either from ignorance or discouragement from previous failures. In the contemplation stage, a person intends to change in the near future but is ambivalent towards change because of his or her acute awareness of both the pros and cons of change. The balance between the pros and cons can lead people to remain in this stage for long periods of time, and often makes them poor candidates for action-oriented programs. In the preparation stage, people intend to make change in the immediate future and have a plan of action for their change, this stage is susceptible to action-oriented programs. In the action stage, people have made specific and overt modifications in their lifestyles which are significant and sufficient to reduce risks for disease. In the maintenance stage, people are working to prevent relapse while employing fewer change processes than in the action stage. Individuals stay in the maintenance stage from 6 months to 5 years before entering the final 
stage, termination. In the termination stage, individuals have zero temptation and reach $100 \%$ self-efficacy. Regardless of circumstances, these people have no desire to return to their unhealthy behavior, as if they never acquired the habit in the first place. Less than one in five people reach this stage of change. Relapse is an additional construct related to the stages of change and refers to the regression from a higher stage of change to an earlier stage of change. People often cycle through the stages of change multiple times prior to successfully achieving permanent change (Prochaska \& Velicer, 1997, p 39). See Figure 1.

Figure 1. Transtheoretical Model of Health Behavior Change

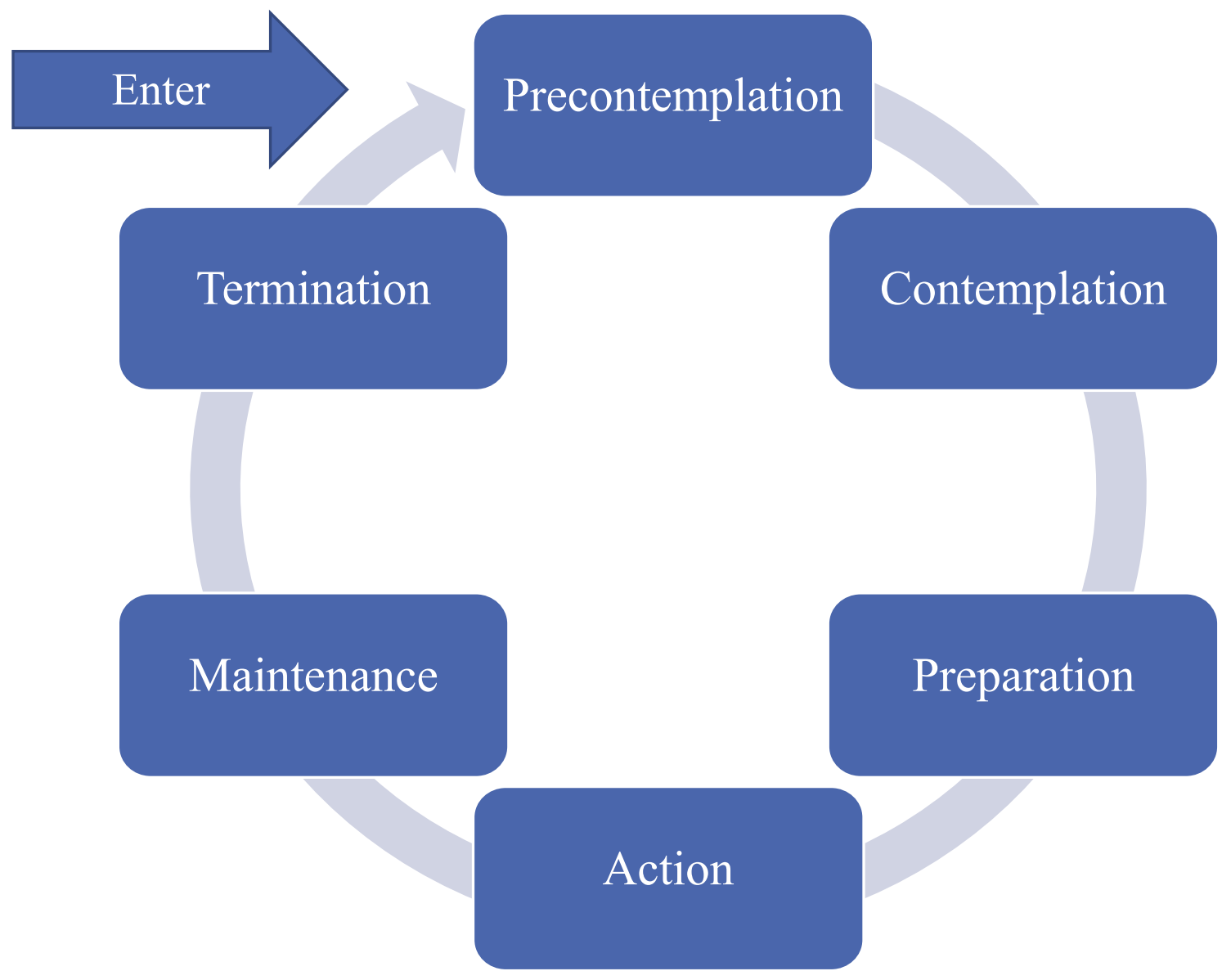

There are ten processes of change which have been identified for producing progress through change, including consciousness raising, dramatic relief, self-reevaluation, 
environmental reevaluation, self-liberation, social liberation, counterconditioning, stimulus control, contingency management, and helping relationships (Prochaska \& Velicer, 1997, p 3940).

The final concepts of the theory are the concepts of decisional balance, self-efficacy, and temptations (Prochaska \& Velicer, 1997). Decisional balance relates to an individual's relative weighing of the pros and cons of change. Self-efficacy is the individual's self-confidence or belief that he or she can cope with specific high-risk situations without relapsing to the known unhealthy behavior. Lastly, temptation refers to the urges to engage in a known unhealthy behavior amid challenging situations (Prochaska \& Velicer, 1997, p 40).

\section{Project}

\section{Institutional Review Board}

The project was reviewed and approved as an expedited study by the West Virginia University Institutional Review Board (IRB) on December 14, 2017. There was limited risk to the participants. Informed consent was obtained from those who agreed to participate in the evaluative portion of the project. There was no deception used as part of the project implementation.

Inclusion criteria. All adults (ages 18 and older) who were (a) active smokers, (b) had lower extremity peripheral arterial disease (PAD), (c) were newly diagnosed with PAD, (d) were cognitively intact, and (e) spoke English were eligible to participate. New patients were targeted for this project because they had multiple encounters within a short period of time to be exposed to the intervention and track behavior change. The Institutional Review Board (IRB) protocol was amended during the enrollment period to include patients with PAD who had developed new problems or symptoms related to the disease. The amendment was approved by the IRB on 
February 8, 2018. Patients with new problems or symptoms were added during the enrollment to increase sample size and were believed to be very similar to newly diagnosed patients. The inclusion criteria were in line with the theoretical framework of the project, specifically the process of consciousness raising, which involves increased awareness about the causes, consequences, and cures for a problem behavior. The hypothesis was that a new diagnosis or new problems with the disease would cause these patients to be more receptive to education, and more likely to be struck with a call to action, providing a teachable moment.

Recruitment and enrollment. The investigator and the medical assistants were responsible for identifying individuals who were new patients who were active smokers with PAD as recipients of disease-oriented smoking cessation education. The investigator determined which patients met remaining inclusion criteria and asked them of their willingness to participate in the evaluative portion of the intervention. In addition to receiving the smoking cessation education, participants who met inclusion criteria were asked to provide additional feedback after the intervention and have additional information recorded as part of the evaluation of the project. They were also given an information sheet about the project and informed consent was obtained prior to proceeding with the intervention.

\section{Intervention}

Preparing for the intervention. Prior to IRB approval, the investigator obtained training in motivational interviewing and became certified as a tobacco treatment specialist to learn how to better help people successfully quit smoking utilizing evidence-based education and therapeutic interventions. The motivational interviewing skills were used to coach people toward behavior change and help move them through the stages of change. A smoking cessation education curriculum was created to provide patients identified as smokers with peripheral 
arterial disease (PAD) with disease-oriented smoking cessation education tailored to the individual's readiness to change. Pre-and post-intervention interview questions were developed for participants related to smoking and PAD which helped evaluate their understanding before and after the intervention.

Brief intervention plan. After being screened for inclusion criteria, participants who met inclusion criteria received the brief intervention based on the 5 A's of smoking cessation: Ask, advise, assess, assist, and arrange (MDQuit, 2012a). The investigator (a) asked the participant if it was okay to talk about his or her smoking, (b) assessed the participant's smoking by performing a comprehensive smoking history using a standardized tobacco cessation interview form, (c) used information from the assessment of the smoking history to advise each participant to quit by providing disease-oriented education about smoking and its relationship to peripheral arterial disease, (d) assisted participants through education on available cessation methods and their proper use and efficacy, and (e) arranged follow up for all participants. After implementation of the $5 \mathrm{~A}$ 's, participants were asked to participate in the evaluative portion of the intervention.

Screen patients. First, patients were screened for inclusion criteria, then asked if it was okay to talk about his or her smoking. Patients were then asked if they would be willing to evaluate their experience after the intervention. The information sheet was reviewed with those who agreed to participate, and informed consent obtained. Next, a brief interview was conducted using semi-structured questions to capture the participant's perspectives on smoking. The interview began by thanking the individual for participating in the project and agreeing to let the investigator help him or her stop smoking. The questions from the interview included: (a) What are some of the reasons you smoke?, (b) what are the situations or places you find yourself 
smoking most often?, (c) what thoughts do you have about quitting smoking?, (d) what have you done to try to quit in the past?, (e) what stopped you from quitting up to now?, (f) have you ever tried to change a different behavior in the past?, (g) what helped you to be successful with changing that behavior?, (h) what do you think the hardest barrier to quitting would be today?, (i) how successful do you think you would be if you tried to quit now?, (j) what kind of assistance do you think you would need?, (k) how do you think your family and friends would react?, (l) what is your understanding of the impact of smoking and your health?

Smoking assessment. Participant's smoking was assessed using a standardized tobacco cessation interview form. The comprehensive smoking history included past medical history and social history such as occupation, lifestyle habits such as exercise, caffeine consumption, alcohol consumption and illicit drug use. Additional smoking history was gathered including number of cigarettes smoked per day, number of years smoking, how much time before they have their first cigarette upon waking, and information about cravings such as having trouble not smoking where prohibited and if they smoke even if they are ill and in bed most of the day. The questions from this section are from a well-known, validated smoking assessment instrument known as the Fagerstrom test for nicotine dependence (NIDA). This instrument assesses the intensity of physical dependence to nicotine based on consumption, compulsion to use, and dependence. The scoring is based on scoring yes/no items with a zero or a one and multiple-choice items from zero to three with a final score yield from zero to ten. Higher scores indicate a more intense physical addiction to nicotine, which is an important assessment tool when considering readiness and ability to quit (NIDA). The questions from the scoring instrument were also used to describe the participants' smoking behaviors and tobacco dependence. 
Readiness to quit was assessed quantitatively by using a self-rating scale and qualitatively by asking if participants believed they could quit. These self-rating data were quantified and used to describe the sample. A stage of change was assigned to each participant based on self-rating data and qualitative information from the interview. Additional history gathered included reasons for smoking, reasons for wanting to quit, if applicable, and what barriers they could identify. Finally, quit attempt history including number of quit attempts, methods used, and family or social support was assessed.

Advise participants to quit. Information from the assessment of the smoking history was utilized to advise each participant to quit by providing disease-oriented education about smoking and peripheral arterial disease (PAD). The 5 R's helped guide smoking cessation interventions; the 5 R's include relevance, risk, rewards, roadblocks, and repetition (Fiore, et al., 2008). The education points included (a) smoking is the leading modifiable risk factor associated with PAD, and only the individual can change or modify this risk factor; (b) smoking cessation can reduce the symptoms related to PAD without any other intervention, and this lifestyle change could potentially eliminate the need for medication or surgery; (c) smoking increases the risk of complications related to PAD, including complications during, after, or without surgical intervention; (d) recurrent disease after complications can be more difficult to treat, and can lead to worsening disease and morbidities such as chronic pain or even limb loss; and (e) people with PAD are at an increased risk of having other atherosclerotic diseases such as coronary artery disease, which can lead to heart attacks, or carotid or cerebral artery diseases which could lead to strokes.

After presenting all the educational intervention related to smoking and peripheral arterial disease and advising participants to quit smoking as part of their medical management plan, they 
had the opportunity to decide if they were prepared to commit to quitting at the time of the encounter. None of the participants committed to quitting during this study. Participants were encouraged to keep the education they received in mind, and the investigator summarized the information collected and the education given during the encounter.

Assisting the quit attempt. Participants were educated using evidence-based tobacco cessation methods. All smoking cessation methods were explained, including "cold turkey", nicotine replacement therapy, and pharmacotherapy. Relevant data related to efficacy and correct utilization of each method was discussed. After educating on all available options, the investigator, together with the individual, made a recommendation for their best option(s).

Importantly, although none of the participants committed to quitting, the "STAR" acronym was discussed. Participants were educated that once a decision was made to quit smoking, they should: 1) set a quit date; 2) tell family, friends, and coworkers about their decision; 3) anticipate challenges; and 4) remove tobacco products from the environment (Cornuz, 2007).

Arranging follow up. Follow up was arranged for all participants based on their next clinic appointment. During this encounter, the smoking history was updated, they received additional brief education on the importance of quitting as it related to their disease process, and they again were advised to quit using study protocol. Participants who did not have a follow up scheduled or missed their follow up were contacted by telephone.

Participant evaluation of the intervention. At the three-month encounter, after the 5 A's were implemented, the participants who agreed to participate in the evaluative portion of the intervention were given a brief interview using semi-structured questions to evaluate their thoughts and feelings about the intervention. Participants were encouraged to provide honest 
feedback and constructive criticism. They were informed that there were no right or wrong answers to the questions, but that the questions will simply help the investigator better understand how to help people manage their smoking and peripheral arterial disease, so they have better outcomes. The questions started with asking how they have done with their smoking since the first visit. Then they were asked how the smoking cessation intervention that was provided impacted their smoking and if they made a quit attempt. Then they were asked what about the intervention they found helpful, and what made those aspects of the intervention helpful for them. They were also asked if there were any aspects of the intervention that weren't as helpful, and what made them less helpful in their experience. They were asked how the intervention differed from other smoking cessation interventions they had experienced in the past, and if the differences were helpful or not helpful. Finally, they were asked what they would change about the intervention that could make it more beneficial to future patients. The information gathered from the interview was recorded in an electronic log and saved for qualitative review during post intervention analysis.

\section{The Transtheoretical Model and Smoking Cessation}

The theoretical model used for the development and implementation of the intervention supported this project because of its historical origin to smoking cessation. Smoking cessation is associated with the Transtheoretical Model, and much of the initial research was related to smoking cessation. Since that time, the model has been developed and tailored to many other health behaviors. Utilizing the model to help match the intervention to the stage of change a person presented in was important to the project. Research related to the Transtheoretical Model finds that $40 \%$ of at risk persons reside in the precontemplation stage of change, while $40 \%$ lie in 
contemplation, and 20\% in preparation (Prochaska \& Velicer, 1997, p. 41). Understanding this distribution helped tailor the intervention to meet the needs of the patients.

Of the ten processes of change which help make up the theory, four closely relate to the project and are defined further in relation to the project. Consciousness raising involves increased awareness about the causes, consequences, and cures for a problem behavior. A goal of the project was to improve awareness of the disease to patients through disease-oriented smoking cessation education. Interventions that can increase awareness include feedback, education, and confrontation. Self-liberation is both the belief that one can change and the commitment to act on that belief (Prochaska \& Velicer, 1997, p 40). Motivation research indicates that people with more choices have greater commitment. For example, patients can be provided a choice on how to attempt smoking cessation; action choices for patients are cold turkey, nicotine fading, and nicotine replacement. Counterconditioning requires the learning of healthier behaviors that can substitute for problem behaviors, such as nicotine replacement, relaxation to counter stress, and assertion to counter peer pressure. Helping relationships combine caring, trust, openness and acceptance as well as support for the healthy behavior change. Rapport building, a therapeutic alliance, follow up calls, and buddy systems were sources of social support experienced during the intervention (Prochaska \& Velicer, 1997, p 40).

\section{Feasibility}

A major consideration for the practice change was whether it was feasible. Feasibility for the practice change included being cost-effective, having the support of management, and being compatible with clinic processes. 
Budget. The budget for the project included all the costs and the revenue incurred as part of implementing the change project in the clinic. First, the cost of the nurse practitioner providing education. This extra time was calculated using five-minute units calculated at $\$ 4.16$ per unit. The smoking cessation education was conducted after the problem-focused encounter and was billed as an "in addition to" service, meaning it was a separately billable service in addition to the problem focused visit. The revenue generated from this additional coding varied by payor and length of education provided. Patients received between three and ten minutes of education were billed using the Current Procedural Terminology (CPT) code 99406, while those receiving more than ten minutes of education were billed using the CPT code 99407. Most patients were billed using the 99406 CPT code for education between three and ten minutes in length, with the average revenue generated among payors being $\$ 13.53$. Patients who received more than ten minutes of education generated an average of $\$ 26.00$. See table 1 .

The cost of the tobacco treatment specialist training was also considered, a one-time cost for a course any healthcare professional can take to become qualified to provide and bill for tobacco cessation education. The investigator's course was obtained for $\$ 445.00$. Printed materials to implement the project included 5 pages of information per participant which summarized information about the intervention for consent purposes. The printing costs were calculated at a rate of $\$ 0.10$ per page, or $\$ 0.50$ per participant. The staff involved in implementation also had to be educated and trained on how to screen patients eligible for the education. For this project, about ten minutes was spent educating the medical assistants on the developed process and was incorporated into a monthly staff meeting. The time spent to screen each patient was less than one minute and thought to be negligible to the project budget. 
Cost-benefit. One of the top factors in feasibility is whether the benefits of the intervention outweigh the costs of implementation. During the study, twenty patients received smoking cessation education which was documented as an "in addition to" service in the medical record. Among these patients, sixteen received three to ten minutes of education while four received greater than ten minutes of education. The formula to calculate the revenue is $\mathrm{X}_{1}$ (number of 3-10 minute interventions) x $\$ 13.53+\mathrm{X}_{2}$ (number of 10 or more minute interventions) x $\$ 26.00=\mathrm{Y}$ (total revenue). The extra revenue generated was estimated at $\$ 320.48$. The time the nurse practitioner spent performing the education was calculated based on units. For the analysis, five minutes of time was calculated for patients billed for three to ten minutes of education with ten minutes of time calculated for those who received ten or more minutes. The formula for the implementation cost is $X_{1}$ (number of 3-10 minute interventions) $\mathrm{x}$ $\$ 4.16+\mathrm{X}_{2}$ (number of 10 or more minute interventions) $\mathrm{x} \$ 8.32=\mathrm{Y}(\mathrm{NP}$ implementation cost). Using this formula, the nurse practitioner's time was calculated at a cost of $\$ 99.84$. Printed materials for the education was calculated at $\$ 0.50$ per person, for a total of $\$ 10$. The formula for net revenue is $\mathrm{Y}_{1}($ total revenue $)-\mathrm{Y}_{2}($ implementation cost $)-$ printed material cost $=$ net revenue. Therefore, the total additional revenue generated by the intervention exceeded the cost by $\$ 210.64$.

Table 1. Project Budget

\begin{tabular}{|l|l|l|l|}
\hline Expense & Per diem & $N$ & Cost \\
\hline Nurse Practitioner & $\begin{array}{l}\text { \$4.16 per unit (5 } \\
\text { minutes) }\end{array}$ & $\begin{array}{l}16 @ 5 \text { minutes } \\
4 @ 10 \text { minutes }\end{array}$ & $\$ 99.84$ \\
\hline Printing & $\begin{array}{l}\$ 0.10 / \text { sheet, 5 sheets } \\
\text { per participant }\end{array}$ & 20 & $\$ 10.00$ \\
\hline Billable Services & $\begin{array}{l}\$ 13.53 \text { CPT 99406 } \\
\$ 26.00 C P T 99407\end{array}$ & $\begin{array}{l}16 @ 99406 \\
4 @ 99407\end{array}$ & $(\$ 320.48)$ \\
\hline Total & & & $(\$ 210.64)$ \\
\hline
\end{tabular}

CPT $=$ Current Procedural Terminology, 99406 = CPT code for three to ten minutes education, $99407=$ CPT code for greater than ten minutes of education 
Projected costs and benefits. The pilot project was implemented to a small subpopulation within the clinic. In one year, there are over 2,800 patient encounters within the clinic. Analysis revealed that $24 \%$ or approximately 672 of those patients are active smokers. Nearly all these patients would benefit from smoking cessation to improve their vascular and overall health and would be potential candidates for smoking cessation education if the project was expanded in the clinic. If each active smoker received smoking cessation education for five minutes, it would cost $\$ 4.66$ per patient while bringing in average revenue of $\$ 13.53$. Therefore, adding this service as part of standard care for all smokers could generate as much as $\$ 5,960$ annually.

Resources. The resources required for this intervention included a dedicated staff that bought into the project, the electronic medical record, and financial resources including the time required of the investigator to implement the intervention and the costs of printed materials.

Staff. Staff were trained in identifying persons who smoked and had a diagnosis of peripheral arterial disease (PAD) so they could be properly identified as appropriate recipients of the intervention. Staff also documented an up-to-date smoking history for each participant in the medical record to help the investigator with data collection and identifying individuals who met inclusion criteria. Finally, the staff scanned relevant data into the electronic medical record.

The clinic has two to three medical assistants responsible for patient care during each clinic day. During Monday, Wednesday, and Friday clinic times, only the nurse practitioner was in clinic, and was easily able to identify patients with PAD and provide the intervention as it was designed. On Tuesdays and Thursdays there were at least two providers in clinic, which is when the medical assistants were utilized to help flag patients who met the inclusion criteria to receive the intervention, regardless of which provider was seen. 
Organizational factors. The mission of the practice is to provide excellent care for patients with vascular disease and to limit disability associated with their disease. This aligned well with the goals of the project as smoking is a major contributor to the development of vascular disease, and to morbidity and mortality after diagnosis. The practice is an independent vascular surgery specialty clinic which is owned and operated autonomously from the hospital; this makes cost-effectiveness a priority. The clinic has a high patient volume with over 100 patient encounters a week and has three providers, a physician and two nurse practitioners. The number and workload of providers had to be considered when implementing a project that required more time for select patient encounters. Patient volume, proper documentation and coding, and efficient utilization of resources are all important to an independent practice which requires a positive cash flow. The project helped increase revenue by providing additional services to some patients, which, with proper documentation and coding, provided additional reimbursement for the services provided.

Key site support. The medical director is a vascular surgeon and has shown interest in the goals and outcomes of the project throughout the process. He has offered input and support for the project. He has stated that he would like there to be a publication involved with the project, which will be good for dissemination of the outcomes to the medical community. Other staff members, too, bought-in to the project and were instrumental in its success.

\section{Project Objectives}

There were five objectives identified for this project. Two process or formative objectives and three outcome or summative objectives. The two process objectives were: 1) By the conclusion of the intervention, $75 \%$ of newly diagnosed patients with peripheral arterial 
disease will have received the defined intervention, and 2) after the study, the participants would believe that the intervention was helpful and disease-oriented.

The three outcome objectives included: 1) After the intervention, smokers who received disease-oriented smoking cessation education would have reduced the number of cigarettes they smoked daily by at least $50 \%$; 2) after the intervention, smokers receiving the intervention would have moved at least one stage forward in their readiness to change, and 3) after the project, a cost/benefit analysis would show that the intervention was at least cost neutral.

\section{Evaluation of Data}

The project was evaluated using both quantitative and qualitative data to evaluate acceptability to participants, effectiveness of the intervention to support smoking cessation, and the cost-effectiveness of the intervention within a specialty practice.

Process evaluation plan. The first objective for process evaluation was the qualitative evaluation of whether participants found the intervention to be helpful. This objective was evaluated using narrative data gathered from patient interviews pre-and post-intervention. Participant's evaluation of the helpfulness of the intervention was captured through narrative responses to the post-intervention interview. Pre and post-intervention stage of change were also evaluated using narrative responses. Responses to the questions from the interview were documented in the investigator's log book. Data from the investigator's log book were evaluated using thematic analysis.

The second process objective was that $75 \%$ of smokers with a new diagnosis of or problem related to peripheral arterial disease (PAD) would receive smoking cessation education. This was evaluated utilizing chart review to determine how many people who had both a documented smoking history and diagnosis of PAD received smoking cessation education. 
Outcome evaluation plan. There were three outcome objectives evaluated for the project. Outcome one was evaluated by comparing the number of cigarettes smoked preintervention to number of cigarettes smoked three months after the intervention. Outcome two compared differences in readiness to change prior to the intervention and again three-months after the intervention based on the Transtheoretical Model. Outcome three was evaluated using a brief cost-benefit analysis which was performed using data related to the costs of implementing the project versus revenue generated from the education as evidenced by a comparison of revenues generated by successful documentation, coding, and reimbursement for tobacco cessation intervention with the expenditures dedicated to the project.

\section{Results}

The analysis of the qualitative and quantitative data revealed interesting information about the intervention and its impact on the participants. The sample is described, followed by pre-intervention data, post-intervention data, and finally final outcomes reported by objectives.

Sample. During the implementation of the project, there were 394 patients who had a diagnosis of peripheral arterial disease (PAD). Among this group, 102 were active smokers, 101 were non-smokers, and 191 were former smokers. Ninety-one patients who had a chief complaint of PAD were screened for inclusion in the project. Twenty-nine active smokers had a new diagnosis or problem related to PAD. Among these, 20 had documented education related to smoking and PAD. The final sample included 9 participants who were willing to talk about their smoking and evaluate the intervention.

Nine participants, 5 males and 4 females, agreed to evaluate the evaluation component of this project. All participants were white, with an average of 59.1 years of age (range 52-67 years of age). Participants smoked an average of 40 years (range 25-50 years) at about one pack (19.77 
cigarettes) a day (range 8-35 cigarettes). There were four participants with Medicare and three with Medicaid, the other two had private insurance.

Pre-intervention assessment. As a group, the sample was in the contemplation stage at their first visit, with participants ranging from pre-contemplation to action stage. Their Fagerstrom score averaged 5.3 (range 2-8), which represents moderate dependence to nicotine (NIDA). The group response to the question whether they were ready to quit had average 6.8 (range 1-10).

Pre-intervention interview analysis. Descriptive data from the pre-intervention interview revealed information about why participants smoked and other information about their smoking history.

Smoking behaviors and quit attempts. There were some common themes among participants for reasons they smoked, such as stress (7), habit (4), and inability to quit (5). Participants reported smoking the most in their car (4), after meals (4), and in social settings (3). Many believed they needed to quit (8), either for their health (5), because their family wants them to (3), or because it is expensive (4). Most of the participants had attempted to quit in the past (8), with everyone having attempted to quit cold turkey in the past, and many others having tried some form of nicotine replacement (6). Three participants had tried a pharmacologic cessation aid, and two others stated they had thought about it but were afraid of side effects.

Motivators and barriers. More than half of the patients had successfully changed a different behavior (5), most of those having quit alcohol (3), with one having been previously dependent on pain medication. Health (3) and necessity (2) were the most commonly cited reasons these participants gave for being successful. Stress (6), previous failures (3), and withdrawal symptoms (4) were the main reasons participants gave for not quitting smoking to 
date. The participants' most difficult barriers to quitting were similar to reasons they smoke and what has stopped them up to now; they cited stress (6), habits (4), and years smoking (3) as biggest barriers.

Smoking cessation self-efficacy. The participants were not optimistic about their ability to quit, with only a few believing they could successfully quit with help (3).

Smoking cessation facilitators. Mentorship from former smokers (2), willpower (3), and environmental changes such as friends and family quitting (3) were all common answers to what assistance would be needed to successfully quit. All but two participants stated that friends and families would be supportive of quitting smoking, with the other participants being unsure if they could get their spouse or significant other to quit with them or "buy in" to their quit attempt (2).

Impact of smoking and health. The participants had difficulty answering the question of what their understanding was about the impact of smoking and their health. Prompting was required for many to provide a response to the open-ended question. Participants believed that smoking was not good for their health. Most stated that it affected their breathing (5), and a few stated they were worried about the risk of a heart attack (4). None responded that their current issues with peripheral arterial disease may be related to smoking. Interestingly, several (3) participants stated that they believed it was too late to change their health by quitting smoking, with one stating that "something had to kill him", and it wasn't worth quitting at his age.

Post-intervention. After the intervention, the group moved forward in their readiness to change, from the contemplation stage to the preparation stage. They ranged from the precontemplation stage to the action stage. One patient quit smoking during the study for about one-month but returned to smoking three cigarettes daily by the three-month follow up. Another patient reported as quit at the three-month follow up encounter, however she had just been 
discharged from the rehab facility where she was unable to smoke. The group averaged about 19.8 cigarettes a day at the first visit, which decreased to about 7.75 cigarettes (range $0-10$ cigarettes) by their three-month follow-up.

Post-intervention interview analysis. A thematic analysis was performed on interview data collected during the three-month follow-up interview. Information from the interviews was used to identify themes related to participants' thoughts on whether the intervention was helpful. As a group, the majority answered that the intervention was helpful (5), while two participants stated they could not recall the education to make a judgement. There were three recurring themes from the question about what was helpful: 1) Conversation (3), 2) fear or stress (3), and 3) thinking (3). The fear could be a positive response, as one patient said the intervention was eye-opening and put the "fear of God" in him to make a change for his health. The following themes reflected what the group did not find helpful: 1) Length of talking (3), 2) too much information (2), and 3) stress (5). One participant stated no provider had spent "that much time talking" to her about smoking, and that our conversation was the first time she became mad at a provider over the conversation about smoking. Their thoughts on the difference in this intervention from others included: 1) Longer conversation (4), 2) not forceful (3), and 3) thought-provoking (3). For those who offered feedback on what could be changed about the intervention, the recommendations to stay brief (2), provide more written information (2), and creating a "cigarette 12 steps program" (1) were the most enlightening.

The interviews also revealed other information that was meaningful qualitative data for this study. The conversations with participants revealed actions they had taken related to smoking over the three-month period, barriers they faced, and successes they had. Many patients admitted to thinking more about their smoking and had made some attempts to cut back (4). 
Two patients had called the quitline and obtained nicotine replacement products to try to help them reduce their smoking. Participants identified stress as a big barrier to quitting. Most participants identified the first cigarette of the day as the most difficult to eliminate and were unsure of what they could do to change habits to eliminate all cigarettes smoked throughout the day (4). Several participants pointed out that other conditions such as chronic obstructive pulmonary disease (COPD) made them more fearful and motivated them to attempt to quit (3). One participant specifically states that her lung doctor got her to commit to quitting after a hospitalization from COPD. She admitted that this intervention likely opened the door to thinking more about her smoking, but that the COPD scare really pushed her through.

Process and outcome evaluation. The final evaluation of the outcomes revealed whether the objectives of the project were met.

Process evaluation. There were two process objectives which were evaluated.

Objective 1. Twenty-nine patients presented with a new or newly complicated diagnosis of peripheral arterial disease. Among those, 20 had documentation of smoking cessation education during their visit. Therefore, about $69 \%$ of patients who met inclusion criteria received the intervention, short of the goal of $75 \%$.

Objective 2. After the study, most of the participants (6) believed that the intervention was helpful and several stated that the content about their disease was thought provoking and made them more concerned about their smoking (3).

Outcome evaluation. There were three outcome objectives which were evaluated.

Objective 1. After the intervention, participants who received disease-oriented smoking cessation education reduced the number of cigarettes they smoked daily from an average of 19.77 to 7.75 , a difference of $60.8 \%$, greater than the goal of $50 \%$. 
Objective 2. Participants who received the intervention moved forward 1.0 stages, which met the goal of moving at least one stage forward in their readiness to change.

Objective 3. After the project, a cost/benefit analysis revealed that the intervention was cost-effective; the total additional revenue generated by the intervention outweighed the cost by $\$ 210.64$.

\section{Discussion and Recommendations}

\section{Challenges}

Many of the goals of the intervention were met and positive quantitative and qualitative data were revealed during the study. However, there were several challenges met during implementation that limited the study and are addressed in this section.

Sample size. During project implementation, the educational intervention was provided to twenty patients in the clinic. Nine patients agreed to participate in the project evaluation. Notably, the small sample size limited both quantitative and qualitative evaluation. Additionally, one patient could not be reached for telephone follow up and did not attend their follow up appointment, leaving only eight patients for final evaluation. Despite the small sample size, this pilot study provided useful information about the feasibility and potential effectiveness of implementing a smoking cessation education program into a specialty clinic setting.

Barriers to recruitment. There were unforeseen circumstances which led to a smaller than expected sample size for this project. First, during implementation it was discovered that fewer patients than anticipated were active smokers. Many patients had quit smoking, but it was not reflected in their medical records. Additionally, there are many patients, especially older patients, who deny any history of smoking. To counter this barrier, Institutional Review Board 
approval was obtained to modify the inclusion criteria to include patients with new problems related to peripheral arterial disease to increase the number of individuals eligible to participate.

Importance of proper documentation. Clinicians in all practice settings should take extra care to ensure that proper documentation of patient history occurs at every encounter. The implementation of this change project revealed that many patients had outdated information in the social history related to smoking, such as being documented as a current smoker although they had quit. This information should be considered when deciding whether an intervention could be cost-effective in a clinical setting, as having fewer smokers than anticipated will decrease the available population to deliver an intervention.

\section{Results and Implications}

The analysis of the qualitative and quantitative data revealed interesting information about the intervention and its impact on the participants. Further discussion regarding the preand -post-intervention data is discussed in this section.

Analysis of pre-intervention qualitative data. The pre-intervention interview and other intake information provided useful narrative data regarding where patients were prior to the intervention. The interview provided insights into their smoking behaviors and previous quit attempts, motivators and barriers to quitting, their self-efficacy regarding smoking cessation, and smoking cessation facilitators.

Smoking behaviors and quit attempts. There were some common themes among participants for reasons they smoked, their behavior patterns with smoking, and their previous attempts to quit. The data suggests that smoking affects many people in similar ways, but it does not make it easier to quit. An important consideration from the data is that many smokers want 
to quit, and most have tried in the past. When implementing an intervention, gaining an understanding of your sample will help better tailor the intervention to their needs.

Motivators and barriers. Stress, previous failures, and environmental barriers are all common reasons that people fail to quit. Stress is present in everyone's lives, although it varies widely in types and amounts. Addressing reasons for stress and teaching alternative coping mechanisms can help break down this common barrier. Common environmental factors include smoking in the car, after meals, or in social settings. These common smoking triggers can be individually explored with follow-up questions to gather more about the underlying reasons that may be leading to recurrent failures to quit. Expanding on the interview can open more opportunities to implement the 5 R's, which incorporate the concepts of relevance, risk, rewards, roadblocks, and repetition.

Smoking cessation self-efficacy. Smokers and providers not understanding the underlying reasons patients smoke and why previous quit attempts have failed can lead to the issue of poor self-efficacy, or individuals not believing they can successfully quit, which was reflected in the data.

Smoking cessation facilitators. The participants offered some insight into poor selfefficacy could be encountered, such as utilizing former smokers to mentor current smokers toward a successful quit. Otherwise, serious health issues or "necessity" may be the only strong motivating factors for patients to quit. The participants in this study attributed previous behavior changes such as quitting alcohol or prescription drugs to these reasons. The challenge with tobacco addiction, when compared to alcohol or opioid or drug abuse is that it doesn't alter people's behavior or lead to legal problems, leaving only serious health issues as strong motivators for people to quit, which are often later stages of disease. 
Exploring possible “calls to action" or reasons to quit is part of the $5 \mathrm{R}$ 's and is a major consideration for individuals developing a smoking cessation intervention. The participants in this study had low self-efficacy from previous failures and were not strongly motivated to quit for their peripheral arterial disease, but they did reduce their smoking over the course of the study. The literature discusses the dose-dependent relationship between smoking and peripheral arterial disease, and although complete cessation is ideal, significant reductions should be valued.

Health priorities. Health, wellness, and quality of life are all important aspects to consider when developing and implementing health promotion or disease prevention interventions. It is important, however, to consider that individuals have different priorities regarding their health and lifestyle choices. Educating individuals about their behavior and why it is unhealthy may be ineffective if they are already aware of the information but do no not care to change. This was demonstrated during this intervention, as one participant explained that he thought it was too late to quit and he didn't have the desire to. His belief was that something had to kill him, and it wasn't worth quitting at his age. Alternatively, there were participants who found the disease-oriented smoking cessation education to be thought-provoking, with some having a fearful response to how continued smoking may impact their disease in the future. For these individuals, education may lead to a call to action to change their behavior.

Analysis of post-intervention qualitative data. The sample for the study found the intervention helpful, but notably, many found it hard to recall the intervention in detail. A larger group may reveal more insights into what was helpful and why. There were many important ideas that emerged from the narrative data gathered from participants about the intervention, such as opinions on the length of the conversation, the amount of written information desired, the 
willingness of people to try pharmacological options for smoking cessation, and individual's priories regarding health.

Length of conversation. Participants in the study expressed different opinions on the length of the conversation during the smoking cessation education. The recurring theme was that in investigator spent more time discussing smoking cessation than they were accustomed to. What differed was participants opinions and preferences on whether the conversation was too long. When developing or implementing an intervention related to uncomfortable topics, one must consider participants' preferences on length of conversation and be able to tailor the intervention based on how long an individual is willing to spend on the topic. Being able to read cues that you are losing an individual's attention should bring you to a stopping point where you can summarize information, then potentially provide a written summary of the education.

Written information. The amount and type of written information provided during an intervention is another important consideration. Written information can be a good tool to reinforce, summarize, or supplement verbal education provided to patients. Participants in the study offered recommendations for the amount and type written information for the study. Some recommended more than the summary the was provided to be included. Other options could include activities for participants to complete at home between encounters or "fact sheets" about smoking in general. These are often included in community smoking cessation classes and could be useful in the clinic setting as well. Additionally, one participant recommended a " 12 step for cigarettes". This could be developed and put into written for and provided to patients as part of supplemental information and/or incorporated into the verbal education. 
Cessation aides. There are multiple options for approaches smokers can utilize for smoking cessation. For this intervention, all options were discussed as available options, including "cold turkey", nicotine replacement, or pharmacological aides. Most participants had tried both quitting cold turkey or nicotine replacement in the past. As a group they seemed comfortable with these methods, although they were not confident in their efficacy given previous experiences. Alternatively, pharmacological aides had only been utilized by three of the participants. Among them, two had some success, but one stopped the medication because of side effects. Two other participants expressed concern with the potential side effects of the pharmacological agents and were against their use. When implementing an intervention, it is important to consider all the alternatives available for intervention.

\section{Continuation of the Project}

This pilot project provided insights into the feasibility of implementing a brief but intensive intervention into a specialty clinic setting. At a vascular surgery practice, virtually all conditions treated are impacted by smoking, and anyone who smokes can be educated on the impacts of smoking and their disease process with only small modifications in delivery based on the condition. Implementing this education as the standard of care for all active smokers within the practice will help improve the quality of care, follow evidence-based guidelines, and increase practice revenue.

The project also provided a better understanding of the barriers to incorporating more tobacco cessation education into the practice and what changes would improve care delivery. First, more than one provider within the clinic should be trained in tobacco cessation to be able to reach more patients during high volume clinic days. Alternatively, a non-provider could be 
trained as a tobacco treatment specialist and be designated to follow the treatment protocol and educate patients identified as appropriate recipients of tobacco cessation education.

Implementation in other settings. Education on smoking cessation and assistance with quitting are typical in the primary care setting, but research shows that it is lacking in specialty clinic settings. This project showed that with proper education of staff and commitment to the goal of improving patient care, effective smoking cessation education can be provided in the specialty setting in a cost-effective way. Reimbursement is possible for tobacco cessation education in specialty clinics with proper documentation and coding if performed by a trained or licensed professional. A variety of medical professionals qualify to be tobacco treatment specialists, from physicians to medical assistants, however formal training is not required for reimbursement from licensed professionals.

\section{Attainment of DNP Essentials}

\section{Scientific Underpinnings for Practice}

The development and implementation of this change project required research of the pathophysiology of peripheral arterial disease and smoking along with evidenced-based guidelines for implementing smoking cessation interventions across a variety of settings. Secondly, a new practice approach for smoking cessation intervention in a specialty clinic setting was developed, implemented, and evaluated.

\section{Organizational and Systems Leadership for Quality Improvement and Systems Thinking}

The developed intervention was a problem-focused clinical practice initiative intended to improve the quality of care delivered within the organization. The cost-effectiveness of the practice change initiative was analyzed to ensure long-term feasibility. 


\section{Clinical Scholarship and Analytical Methods for Evidence-based Practice}

Clinical scholarship was demonstrated through the design and implementation of processes to evaluate the outcomes of the practice change initiative against standard care. Analytical methods were used to appraise existing literature to determine the best methods and to implement and evidence-based intervention.

\section{Information Systems/Technology and Patient Care Technology for the Improvement and Transformation of Health Care}

An important piece of the development and implementation of the project was evaluation of how healthcare technology and the electronic medical record could be utilized to facilitate efficient implementation of the change project.

\section{Health Care Policy for Advocacy in Health Care}

As part of the efforts to fully understand health care policy for advocacy in health care, the centers for Medicaid and Medicare Services and other health insurance policy information regarding coverages and billing for smoking cessation were researched. Information from the project and education provided was documented in the medical record based on available guidelines for billing and coding. This information is useful to other providers in the participants' care team and to demonstrate to insurances that smoking cessation is being discussed or attempted.

\section{Interprofessional Collaboration for Improving Patient and Population Health Outcomes}

An interprofessional team was led by the student to analyze existing practices and develop a new standard of care for implementation in the practice setting. Effective communication and collaboration skills were utilized in implementing best practice using the chosen transtheoretical model. 


\section{Clinical Prevention and Population Health for Improving the Nation's Health}

The student synthesized concepts, including psychosocial dimensions and cultural diversity, related to clinical prevention and population health in developing, implementing, and evaluation interventions to address health promotion and disease prevention efforts in smoking cessation. Additionally, the care delivery model in the project from perspective of community health and the cultural and socioeconomic dimensions of health was evaluated.

\section{Advanced Nursing Practice}

The student developed and implemented an intervention and evaluated it for links among practice, organizational, population, fiscal, and policy issues with a focus on nursing science and other sciences. The intervention involved developing and sustaining therapeutic relationships with patients and health professionals to facilitate optimal care and patient outcomes. 
Appendix I. Tobacco Cessation Interview Form

\begin{tabular}{|c|c|c|c|}
\hline \multicolumn{4}{|c|}{ Tobacco Cessation Interview Form } \\
\hline \multicolumn{4}{|c|}{ TOBACCO USE } \\
\hline 1. & \multicolumn{2}{|c|}{ How soon after you awaken do you smoke your first cigarette? } & \begin{tabular}{|l} 
After 60 minutes $(0)$ \\
$31-60$ minutes $(1)$ \\
$6-30$ minutes $(2)$ \\
Within 5 minutes (3)
\end{tabular} \\
\hline 2. & \multicolumn{2}{|c|}{$\begin{array}{l}\text { Do you find it difficult to refrain from smoking in places where it is } \\
\text { forbidden? }\end{array}$} & $\begin{array}{l}\text { No (0) } \\
\text { Yes (1) }\end{array}$ \\
\hline 3. & \multicolumn{2}{|c|}{ Which cigarette would you hate the most to give up? } & $\begin{array}{l}\text { The first in the } \\
\text { morning (1) } \\
\text { Any other }(0)\end{array}$ \\
\hline 4. & \multicolumn{2}{|c|}{ How many cigarettes per day do you smoke? } & $\begin{array}{l}10 \text { or less }(0) \\
11-20(1) \\
21-30(2) \\
31 \text { or more }(3) \\
\end{array}$ \\
\hline 5. & \multicolumn{2}{|c|}{$\begin{array}{l}\text { Do you smoke more frequently during the first hours after } \\
\text { awakening than during the rest of the day? }\end{array}$} & $\begin{array}{l}\text { No (0) } \\
\text { Yes (1) }\end{array}$ \\
\hline 6. & \multicolumn{2}{|c|}{$\begin{array}{l}\text { Do you smoke even if you are so ill that you are in bed } \\
\text { most of the day? }\end{array}$} & $\begin{array}{l}\text { No (0) } \\
\text { Yes (1) }\end{array}$ \\
\hline \multicolumn{4}{|c|}{ READINESS TO CHANGE } \\
\hline \multicolumn{3}{|c|}{ How badly do you want to quit now (scale $1-10$ ) } & \\
\hline \multicolumn{3}{|c|}{ Do you think you can successfully quit with help? } & \\
\hline \multicolumn{4}{|c|}{ STAGE OF CHANGE } \\
\hline $\begin{array}{l}\square \\
\square \\
\square \\
\square \\
\square \\
\square \\
\square\end{array}$ & $\begin{array}{l}\text { Precontemplative } \\
\text { Contemplative } \\
\text { Planning } \\
\text { Active } \\
\text { Maintenance } \\
\text { Relapse } \\
\text { Recycle }\end{array}$ & & \\
\hline \multicolumn{4}{|c|}{ TOBACCO USE QUESTIONNAIRE } \\
\hline \multicolumn{4}{|c|}{ Why do you smoke? } \\
\hline \multicolumn{4}{|c|}{ Why do you want to quit? } \\
\hline Wha & t are some barriers to quitting? & & \\
\hline
\end{tabular}




\section{QUIT ATTEMPT HISTORY}

Have you ever tried to quit prior to today?

What methods did you use?

Did you have family/friend support?

\section{TRIGGERS}

\section{ADDITIONAL HISTORY DISCUSSED}




\section{Appendix II. Descriptive Questions}

1. How many patients in sample smoke their first cigarette...
a. Within 5 minutes of waking up?
b. 6-30 minutes within waking up?
c. 31-60 minutes within waking up?
d. After 60 minutes of waking?

2. How many patients find it difficult to refrain from smoking in places where it is forbidden?

a. How many do not find it difficult to refrain?

3. How many patients find the first cigarette in the morning the hardest to give up?

a. How many find a different cigarette the most difficult?

4. How many cigarettes a day does patient smoke?
a. 10 or less
b. $11-20$
c. $21-30$
d. 31 or more

5. How many patients fine that they smoke more frequently in the first hours after awakening than during the rest of the day?

6. How many patients said they would smoke even if they were ill and in bed most of the day?

a. How many said they wouldn't?

7. How many patients did not want to quit smoking at all? (1-2/10)

a. How many would consider quitting? (3-6/10)

b. How many are considering quitting? (7-8/10)

c. How many want to or are trying to quit? $(9-10 / 10)$

8. How many patients believe they can successfully quit smoking with help?

a. How many do not believe they can quit?

9. How many patients have tried quitting in the past?

a. How many have never tried?

10. How many patients have tried quitting cold turkey?

a. With nicotine replacement therapy?

b. With prescription medication?

c. With cognitive behavioral therapy?

d. With combination therapy?

11. Average years smoking

a. Range

12. Number of cigarettes smoked per day
a. Range
b. average 
Appendix III. Qualitative Interview Questions

Pre-Intervention

1. What is your understanding of the impact of smoking and your health?

a. Perception of risk

2. What are your reasons for smoking?

3. What are your thoughts about quitting smoking?

a. Do you want to quit?

b. Have you tried?

4. What have you tried to quit smoking in the past?

5. What do you see as barriers to quitting smoking?

6. Do you think that you can quit smoking?

7. How do you think your family and friends will react to your commitment to quit smoking?

\section{Post-Intervention}

1. Do you think that the smoking cessation intervention we provided was helpful to your quit attempt?

2. What about the intervention did you find helpful?

3. What about the intervention did you find as not helpful?

4. How was this intervention different from other tobacco cessation interventions you have experienced in the past?

5. What would you change about the intervention to improve it for future patients? 


\section{References}

Aboyans, V., McClelland, R. L., Allison, M. A., McDermott, M. M., Blumenthal, R. S., Macura, K., \& Criqui, M. H. (2011). Lower extremity peripheral artery disease in the absence of traditional risk factors. The Multi-Ethnic Study of Atherosclerosis. Atherosclerosis, 214(1), 169-173.

Aiman, U., Haseen, M. A., Beg, M. H., Khan, R. A., Siddiqui, F. A., \& Alam, I. (2014). Profile of atherosclerotic risk factors and management in patients of peripheral arterial disease at a tertiary care teaching hospital of North India. Indian journal of pharmaceutical sciences, 76(6), 504-509.

Alexopoulos, N., Vlachopoulos, C., \& Stefanadis, C. (2010). Quitting Smoking: An Action That Does Not Bounce Back. Cardiology, 117(3), 181-183.

Aronow, W. S. (2007). Management of peripheral arterial disease of the lower extremities. Comprehensive therapy, 33(4), 247-256.

Aronow, W. S. (2007). Peripheral arterial disease in the elderly. Clinical interventions in aging, 2(4), 645-654.

Aronow, W. S. (2010). Office management of peripheral arterial disease. The American journal of medicine, 123(9), 790-792.

Au, T. B., Golledge, J., Walker, P. J., Haigh, K., \& Nelson, M. (2013). Peripheral arterial disease: diagnosis and management in general practice.Australian family physician, 42(6), 397400.

Brief Interventions \& 5 A's. (2012, December 04). Retrieved August 29, 2016, from http://mdquit.org/cessation-programs/brief-interventions-5 
Centers for Disease Control and Prevention. (2014). Peripheral Arterial Disease (PAD) Fact Sheet. Retrieved from http://www.cdc.gov/DHDSP/data_statistics/fact_sheets/fs_PAD.htm

Conen, D., Everett, B. M., Kurth, T., Creager, M. A., Buring, J. E., Ridker, P. M., \& Pradhan, A. D. (2011). Smoking, smoking cessation, and risk for symptomatic peripheral artery disease in women: a cohort study. Annals of internal medicine, 154(11), 719-726.

Cornuz, J. (2007). Smoking Cessation Interventions in Clinical Practice. European Journal of Vascular and Endovascular Surgery, 397-404.

Current Cigarette Smoking Among Adults in the United States. (2015, August 25). Retrieved September 14, 2015, from http://www.cdc.gov/tobacco/data_statistics/ fact_sheets/adult_data/cig_smoking/index.htm

Dunkley, A., Stone, M., Sayers, R., Farooqi, A., \& Khunti, K. (2007). A cross sectional survey of secondary prevention measures in patients with peripheral arterial disease in primary care. Postgraduate medical journal,83(983), 602-605.

"Fast Facts." Centers for Disease Control and Prevention. Centers for Disease Control and Prevention, 15 Apr. 2015. Web. 14 Sept. 2015. $<$ http://www.cdc.gov/tobacco/data_statistics/fact_sheets/fast_facts/index.htm>.

Federman, D. G., \& Kravetz, J. D. (2007). Peripheral arterial disease: diagnosis, treatment, and systemic implications. Clinics in dermatology,25(1), 93-100.

Fiore MC, Jaén CR, Baker TB, et al. Treating Tobacco Use and Dependence: 2008 Update. Clinical Practice Guideline. Rockville, MD: U.S. Department of Health and Human Services. Public Health Service. May 2008. 
Hankey, G. J., Norman, P. E., \& Eikelboom, J. W. (2006). Medical treatment of peripheral arterial disease. Jama, 295(5), 547-553.

Haugen, S., Casserly, I. P., Regensteiner, J. G., \& Hiatt, W. R. (2007). Risk assessment in the patient with established peripheral arterial disease.Vascular Medicine, 12(4), 343-350.

Hennion, D. R., \& Siano, K. A. (2013). Diagnosis and treatment of peripheral arterial disease. American family physician, 88(5), 306-310.

Hennrikus, D., Joseph, A. M., Lando, H. A., Duval, S., Ukestad, L., Kodl, M., \& Hirsch, A. T. (2010). Effectiveness of a smoking cessation program for peripheral artery disease patients: a randomized controlled trial. Journal of the American College of Cardiology, 56(25), 2105-2112.

Hiatt, W. R., \& Krantz, M. J. (2006). Masterclass series in peripheral arterial disease Antiplatelet therapy for peripheral arterial disease and claudication.Vascular Medicine, 11(1), 55-60.

Katsiki, N., Papadopoulou, S. K., Fachantidou, A. I., \& Mikhailidis, D. P. (2013). Smoking and vascular risk: are all forms of smoking harmful to all types of vascular disease?. Public health, 127(5), 435-441.

Kröger, K., Dragano, N., Stang, A., Moebus, S., Möhlenkamp, S., Mann, K., ... \& Heinz Nixdorf Recall Study Investigator Group. (2009). An unequal social distribution of peripheral arterial disease and the possible explanations: results from a population-based study. Vascular medicine,14(4), 289-296.

Layden, J., Michaels, J., Bermingham, S., Higgins, B., \& Guideline Development Group. (2012). Diagnosis and management of lower limb peripheral arterial disease: summary of NICE guidance. Bmj, 345, 42-43. 
Lee, Y. H., Shin, M. H., Kweon, S. S., Choi, J. S., Rhee, J. A., Ahn, H. R., ... \& Jeong, S. K. (2011). Cumulative smoking exposure, duration of smoking cessation, and peripheral arterial disease in middle-aged and older Korean men. BMC Public Health, 11(94), 1-7.

Lovell, M., Myers, K., Forbes, T. L., Dresser, G., \& Weiss, E. (2011). Peripheral arterial disease: application of the chronic care model. Journal of Vascular Nursing, 29(4), 147-152.

Lu, L., Mackay, D. F., \& Pell, J. P. (2014). Meta-analysis of the association between cigarette smoking and peripheral arterial disease. Heart, 100(5), 414-423.

Lumsden, A. B., \& Rice, T. W. (2006). Medical management of peripheral arterial disease: a therapeutic algorithm. Journal of Endovascular Therapy,13(2 suppl), II-19.

Madia, C. (2012). Medical and surgical management of peripheral arterial disease. Journal of the American Academy of Physician Assistants, 25(9), 52-56.

Mannava, K., \& Money, S. R. (2007). Current Management of Peripheral Arterial Occlusive Disease. American journal of cardiovascular drugs, 7(1), 59-66.

Moyer, V. A. (2013). Screening for peripheral artery disease and cardiovascular disease risk assessment with the ankle-brachial index in adults: US Preventive Services Task Force recommendation statement.Annals of internal medicine, 159(5), 342-348.

Muir, R. L. (2009). Peripheral arterial disease: Pathophysiology, risk factors, diagnosis, treatment, and prevention. Journal of Vascular Nursing, 27(2), 26-30.

National Institute on Drug Abuse (NIDA). (n.d.) Instrument: Fagerstrom Test for Nicotine Dependence (FTND). Retrieved March 09, 2017, from https://cde.drugabuse.gov/instrument/d7c0b0f5-b865-e4de-e040-bb89ad43202b 
Paraskevas, K. I., Papas, T. T., Pavlidis, P., Bessias, N., \& Andrikopoulos, V. (2008). The importance of conservative measures in peripheral arterial disease: an update. Angiology. $59(5), 529-533$

Prochaska, J. O., \& Velicer, W. F. (1997). Behavior Change: The Transtheoretical Model of Health Behavior Change. American Journal of Health Promotion, 12(1), 38-48.

Screening, Brief Intervention, and Referral to Treatment (SBIRT). (2012, March 09). Retrieved August 29, 2016, from http://mdquit.org/cessation-programs/screening-briefintervention-and-referral-treatment-sbirt

Simmons, A., Steffen, K., \& Sanders, S. (2012). Medical therapy for peripheral arterial disease. Current opinion in cardiology, 27(6), 592-597.

Smoking: Brief interventions and referrals. (2006, March). Retrieved August 29, 2016, from https://www.nice.org.uk/Guidance/PH1

Sontheimer, D. L. (2006). Peripheral vascular disease: diagnosis and treatment. American family physician, 73(11), 1971-1976.

Steffen, L. M., Duprez, D. A., Boucher, J. L., Ershow, A. G., \& Hirsch, A. T. (2008). Management of peripheral arterial disease. Diabetes Spectrum, 21(3), 171-177.

Tobacco. (2015, September 11). Retrieved September 14, 2015, from http://www.healthypeople.gov/2020/leading-health-indicators/2020-lhi-topics/Tobacco

Verma, A., Prasad, A., Elkadi, G. H., \& Chi, Y. W. (2011). Peripheral arterial disease: evaluation, risk factor modification, and medical management.JCOM, 18(2), 74-84.

Watson, K., Watson, B. D., \& Pater, K. S. (2006). Peripheral arterial disease: a review of disease awareness and management. The American journal of geriatric pharmacotherapy, 4(4), 365-379. 
Wiggers, L. C., Oort, F. J., Peters, R. J., Legemate, D. A., de Haes, H. C., \& Smets, E. M. (2006). Smoking cessation may not improve quality of life in atherosclerotic patients. Nicotine $\&$ tobacco research, $8(4), 581-589$.

Wiley, M., Kumar, A., \& Vacek, J. L. (2012). Peripheral Arterial Disease: Diagnosis and Treatment. Consultant, 52, 601-608. 